•研究报告・

\title{
基于人工地物时空变化的自然保护区空间近邻 效应评估：以沙坡头国家级自然保护区为例
}

\author{
刘方正 ${ }^{1}$ 张 鹏 ${ }^{2}$ 张玉波 ${ }^{1}$ 陈 冰 $^{1}$ 杜金酒 ${ }^{1}$ 王 伟 $1^{*} \quad$ 李俊生 ${ }^{1}$ \\ 1 (中国环境科学研究院生物多样性研究中心, 北京 100012) \\ 2 (中国科学院西北生态环境资源研究院沙坡头沙漠研究试验站, 兰州 730000)
}

\begin{abstract}
摘要: 已有研究表明, 建立自然保护区会对其周边生态环境产生影响, 即自然保护区的空间近邻效应。当前, 一些 自然保护区的周边区域生态环境发生了较大变化, 尤其体现在人工地物的时空变化上。研究基于人工地物时空变 化的自然保护区空间近邻效应, 关系到自然保护区及其保护对象长久的生存和安全。为研究空间近邻效应的变化 区间和作用距离, 识别驱动因子，本文以宁夏沙坡头国家级自然保护区为例，对自然保护区周边 $20 \mathrm{~km}$ 范围内的空 间进行分割, 结合1990-2015年遥感影像解译和人工地物提取, 利用Mann-Kendall趋势分析法和驱动因子的相关 性检验分析, 提出了基于人工地物时空变化的空间近邻效应评估技术。结果表明: (1)随着时间的推移, 研究区域内 人工地物面积及景观格局不断扩大和扩张, 人为活动影响在增强。(2)人工地物的空间近邻效应随时间的推移而增 强, 随距离尺度的增加而下降。(3)空间近邻效应的变化趋势在各区间内的显著性和驱动力因子为: 第一区间(1-5 $\mathrm{km})$ 的下降趋势偶见显著性, 驱动力来自防护林; 第二区间 $(6-10 \mathrm{~km})$ 的下降趋势具有显著性, 驱动力来自城镇用 地; 第三区间 $(11-20 \mathrm{~km})$ 的下降趋势具有极显著性, 驱动力来自农田。沙坡头国家级自然保护区建立以来, 周边土 地利用变化受人为作用影响明显, 须引起关注。
\end{abstract}

关键词：自然保护区; 空间近邻效应; 溢出; 泄露; 趋势分析

\section{Assessment of the space neighborhood effect on nature reserves based on temporal and spatial changes of artificial objects: a case study on Shapo- tou National Nature Reserve}

\author{
Fangzheng Liu ${ }^{1}$, Peng Zhang ${ }^{2}$, Yubo Zhang ${ }^{1}$, Bing Chen ${ }^{1}$, Jinhong Du ${ }^{1}$, Wei Wang ${ }^{1 *}$, Junsheng Li ${ }^{1}$ \\ 1 Biodiversity Research Center, Chinese Research Academy of Environmental Sciences, Beijing 100012 \\ 2 Shapotou Desert Research and Experiment Station, Northwest Institute of Eco-Environment and Resources, Chinese \\ Academy of Sciences, Lanzhou 730000
}

\begin{abstract}
It has been shown that the established nature reserves will affect the surrounding ecological environment, that is, the space neighborhood effect on nature reserves. At present, the ecological environment of the surrounding areas of some nature reserves has changed greatly, especially in the temporal and spatial changes of artificial objects. To study the space neighborhood effect on nature reserves based on temporal and spatial changes of artificial objects will do significant help to maintain the survival and safety of nature reserve and its protected objects. To analyze the variation intervals of the space neighborhood effect and the distance scale, and to identify the driving factors, we chose Ningxia Shapotou National Nature Reserve as a case study. We divided the study area within a range of $20 \mathrm{~km}$ around the nature reserve, extracted the artificial objects from the remote image analysis between 1990 and 2015, and used Mann-Kendall trend analysis and driving factor correlation test analysis, to assess the space neighborhood effect of nature reserves based on temporal and spatial changes in artificial objects. Results showed that the areas and patterns of artificial objects were expanding, which meant the impacts of human activities were increasing over time. In addition,
\end{abstract}

收稿日期: 2017-05-04; 接受日期: 2017-08-06

基金项目：国家自然科学基金(31300453)和中国科学院野外站联盟项目(KFJ-SW-YW028)

* 通讯作者 Author for correspondence. E-mail: wang.wei@craes.org.cn 
the space neighborhood effect was most evident with increases in time and decreases in the distance scale. Trends in the space neighborhood effect were divided into three descending intervals, and the driving factors differed. In the first interval $(1-5 \mathrm{~km})$, the trend was occasionally significant, and shelter forest was the main driving factor. In the second interval $(6-10 \mathrm{~km})$, significance of the descending trend could be observed, and building became the driving factor. Lastly, the driving factor was farming, and a very significant descending trend was found in the third interval (11-20 km). Since the establishment of the Ningxia Shapotou National Nature Reserve, its surrounding land-use changes are significantly influenced by human activities, which needs attention.

Key words: nature reserves; space neighborhood effect; spillover; leakage; trend analysis

在各国生物多样性保护实践中, 建立自然保护 区是最为有效的方式(Howard et al, 2000; 王伟等, 2016)。截至2014年, 全球范围内的自然保护区数量 超过 20 万个, 总面积相当于中国国土面积的 3.4 倍 (刘方正等, 2016)。我国自然保护区的建设和发展经 历了 60 余年, 共建成各级自然保护区 2,740 处，总面 积147万平方公里(http://www.mep.gov.cn/stbh/zrbhq /qgzrbhqml/201611/P020161125559865886359.pdf), 保护了 $90 \%$ 以上的陆地自然生态系统和 $89 \%$ 的国家 重点保护野生动植物物种以及重要自然遗迹(陈吉 宁, 2016), 为世界生物多样性保护事业作出了重要 贡献。

空间近邻效应(space neighborhood effect)是指 区域内各种经济、社会活动发生的空间位置对其相 互联系所产生的影响。在经济地理学的研究中, 德 国农业经济学家杜能根据农产品的重量体积、运输 便利性、保鲜能力、产品价值等因素, 围绕社会经 济活动中心，由内及外依次形成自由式农业、林业、 轮作式农业、谷草式农业、三國式农业和畜牧业的 生产方式空间配置格局。杜能农业区划模型阐明了 土地利用方向与社会经济活动中心的空间位置关 系, 是空间近邻效应的典型代表(李小建等, 2006)。 空间近邻效应同样存在于自然保护区及其周边区 域。从目前的研究成果来看, 溢出(spillover)和泄露 (leakage)便是两种效果不同的空间近邻效应, 前者 为正面效果，后者为负面效果。

溢出现象最早见于经济活动研究, 即一个组织 的行为在收获预期效果的同时，对组织之外的人或 社会产生的正面效果。溢出现象在环境政策制定和 生物多样性保护等领域的表现也很突出(Chen et al, 2016; Amin, 2016)。在自然保护区及其周边区域也 存在溢出现象。Russ等(2004)在对菲律宾Apo岛海洋 禁渔保护区(No-Take Marine Reserve)的研究中发现,
两种岩礁鱼类的生物量在经历 18 年的保护后增长 了3倍，并在距离该保护区200-250 m范围内增长显 著, 由此认为海洋禁渔保护区的建立有助于渔业的 可持续发展。类似地，溢出现象也表现在森林火灾 发生率和防控成效方面(Nepstad et al, 2006)。

相对于溢出现象的正面效果，也存在负面效果 的泄露现象, 如建立自然保护区可能将人类活动转 移至保护区周边区域(Ewers \& Rodrigues, 2008)。 Wittemyer等(2008)比较了 306 个自然保护区及其外 围 $10 \mathrm{~km}$ 范围内的人口增长情况, 发现在保护区边 缘附近的人口增长率高于保护区所在地农村的人 口增长率。此外, Oliveira等(2007)在亚马孙流域的 研究发现, 自然保护区内森林受到的干扰和退化较 少, 然而保护区周边邻近区域森林退化显著。 Nagendra等(2004)在洪都拉斯的研究也支持了上述 观点, 他们发现在距离国家公园 $1 \mathrm{~km}$ 范围内出现了 显著的森林退化。

从目前自然保护区空间近邻效应的研究对象 来看, 多以渔业收获量、森林覆盖率、植被质量等 为主, 少有从人口密度切入, 也未见对人工地物的 考察研究。从研究方法上看, 多数学者是在特定时 间段内，在自然保护区边界外划定一定距离尺度的 评估空间，距离尺度的选取和评估空间的位置形状 也并未形成统一标准。例如Wittemyer等(2008)和 Nepstad等(2006)的研究都是选取了 $10 \mathrm{~km}$ 的尺度, 前者是沿保护区外边界形成的环状缓冲区域，后者 则是保护区内外各 $10 \mathrm{~km}$ 宽的带状区域。还有研究 者对距离尺度进行了分组划分，如Russ等(2004)以 及Abesamis和Russ (2005)的一系列研究中分别采用 50-100 m、150-200 m、250-300 m、400 m、500 m 的划分方法; Sanchez-Azofeifa等(2003)的研究则划分 为 $0.5 \mathrm{~km} 、 1.0 \mathrm{~km} 、 10 \mathrm{~km}$; 类似的还有Maiorano等 (2008)按照 $1 \mathrm{~km} 、 2.5 \mathrm{~km} 、 5 \mathrm{~km}$ 的划分, 以及Wright 
等(2007)按照 $5 \mathrm{~km} 、 10 \mathrm{~km} 、 15 \mathrm{~km}$ 的划分等。

为探究自然保护区周边区域的人工地物的时 空变化及其驱动力, 本研究尝试提出了一种自然保 护区空间近邻效应评估技术, 并选择沙坡头国家级 自然保护区，构建了 $20 \mathrm{~km}$ 范围的评估空间，结合 遥感解译获得的近 30 年土地利用情况, 按 $1 \mathrm{~km}$ 为步 长对评估空间进行分割并提取人工地物, 利用 Mann-Kendall趋势分析法和驱动因子的相关性检验 分析, 得出被评估自然保护区在人工地物方面的空 间近邻效应结果, 以期为今后开展类似研究和自然 保护区安全评估提供技术参考。

\section{1 材料与方法}

\section{1 研究区域}

沙坡头位于腾格里沙漠南缘的宁夏回族自治 区中卫市境内, 是东部季风尾问区, 在气候上属我 国干旱和半干旱区的过渡带, 是干旱草原与荒漠景 观的过渡带, 也是灌溉农业和旱作雨养型农业的分 界。这里多年平均降雨量 $186 \mathrm{~mm}$, 年蒸发量 $3,000 \mathrm{~mm}$, 年平均气温 $9.6^{\circ} \mathrm{C}$ (刘迺发等, 2005 ; 李新荣等, 2016)。沙坡头以治沙成就享誉中外, 人工绿色长城 阻止了腾格里沙漠向南侵袭, 保障了包兰铁路的畅
通，为我国西北地区经济发展发挥了巨大的生态保 护效应。经过 30 多年的发展，沙坡头地区的生态和 社会面貌已经发生了巨大变化。三北防护林工程极 大改善了区域的生态环境, 使植被覆盖率得到了显 著增加。与此同时, 围绕黄河和沙漠景观开展的旅 游活动也带动了当地经济发展。

宁夏沙坡头国家级自然保护区始建于1984年, 面积13,722 ha, 主要保护对象为沙漠自然生态系统 和特有的沙地野生动植物资源(国家环境保护总局 自然生态保护司和国家环境保护总局南京环境科 学研究所, 2006)。保护区内外种植有较大面积的人 工防护林。随着旅游活动和建设开发的加大, 自然 保护区周边土地利用类型转变强度进一步增大。本 研究以沙坡头国家级自然保护区为中心, 通过 ArcGIS 10.2软件沿保护区外边界划定 $20 \mathrm{~km}$ 作为研 究区域 (图 1), 地理坐标位于 $37^{\circ} 15^{\prime}-37^{\circ} 48^{\prime} \mathrm{N}$, $104^{\circ} 35^{\prime}-105^{\circ} 24^{\prime}$ E之间, 面积 304,661 ha。

\section{2 数据来源}

遥感数据来自中国科学院地理空间数据云 (http://www.gscloud.cn)。选用Landsat系列卫星2015 年、2010年、2005年、2000年、1995年和1990年6 期遥感影像。影像选择时, 综合考虑并控制了拍摄

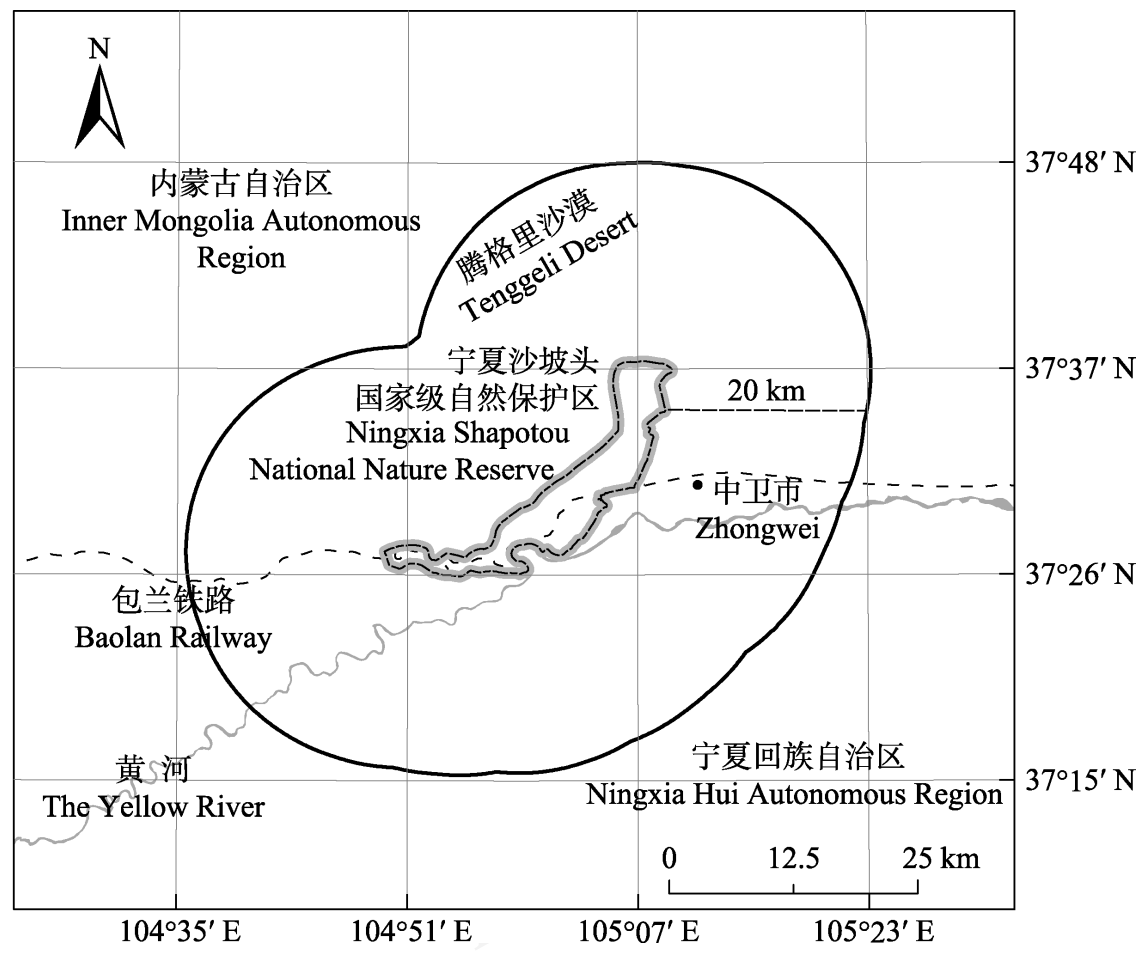

图1 研究区域位置示意图

Fig. 1 The location of the study area 
时间、云量干扰等因素, 研究区域全部位于一景影 像当中(条带号: 130, 行编号: 34)。

2016年10月，在沙坡头国家级自然保护区及其 周边开展实地调查和交流访谈, 布设 3 条调查路线, 总长度约 $50 \mathrm{~km}$, 涵盖了自然保护区四至、各功能区 以及周边社区。获得并建立了研究区域遥感解译标 志, 掌握了研究区域的社会经济发展过程。

\section{3 空间近邻效应评估技术}

构建基于人工地物时空变化的自然保护区空 间近邻效应评估技术，主要包括评估空间构建、人 工地物提取和趋势分析与检验 3 个环节, 技术路线 如图2。

\subsection{1 评估空间构建}

使用ArcGIS 10.2软件的缓冲区(buffer)命令, 沿沙坡头保护区边界向外构建评估空间。按照每次 $1 \mathrm{~km}$ 的步长增加距离尺度 $(i, i=1,2, \cdots, 20)$, 依次 获得距离保护区边界 $1 \mathrm{~km}, 2 \mathrm{~km}, \cdots, 20 \mathrm{~km}$ 的 20 个 环状区域，完成评估空间的构建。

\subsection{2 人工地物提取}

土地利用类型解译与变化分析是评估自然、经 济、社会演变的有效手段(范泽孟等, 2012; 陈利顶 等, 2014), 关注人工地物格局变化可以有效识别研 究区域内的人为活动强度和来源。选取道路交叉 点、建筑物边界等明显标识完成6期遥感数据的空 间配准。解译分类体系包括人工地物和自然地物两 大类共计 8 种类型，其中人工地物有防护林、农田、 城镇用地和能源用地, 自然地物有天然草地、河流、 湖泊和荒漠。遥感影像的解译结果经实地调查和交
流访谈得到验证，总体精度大于 $90 \%$, Kappa系数大 于 0.87 , 解译分类准确性较高。评估空间内的土地 利用解译和人工地物提取在 ENVI 5.1 和 ArcGIS 10.2 软件支持下完成。

\subsection{3 趋势分析与检验}

将构建的评估空间和人工地物提取结果在 ArcGIS 10.2中进行叠加处理, 统计各环状区域内人 工地物面积占比 $\left(R_{i}\right)$, 按以下公式计算:

$$
R_{i}=\frac{A_{i}}{M_{i}}
$$

式中, $R_{i}$ 为第 $i$ 距离尺度下的人工地物面积占该环状 区域面积的比值; $A_{i}$ 和 $M_{i}$ 分别表示在第 $i$ 距离尺度内 人工地物的面积和环状区域的面积。

空间近邻效应趋势分析与检验选用 MannKendall方法, 该方法是一种非参数统计检验方法, 可以用来判断变化趋势的显著性(Hoaglin et al, 2000; 邓兴耀等, 2017)。使用Mann-Kendall检验的 样本无须服从一定的分布，同时对数据误差的抗干 扰性较强, 能够避免少数异常值的干扰, 已经在气 象、水文、植被长势(Tošić, 2004; 袁丽华等, 2013; 王米雪等, 2014)等研究中得到广泛使用。MannKendall方法的统计量Z按公式(2-5)计算:

$$
Z=\left\{\begin{array}{l}
\frac{S-1}{\sqrt{s(S)}}, S>0 \\
0, S=0 \\
\frac{S+1}{\sqrt{s(S)}}, S<0
\end{array}\right.
$$

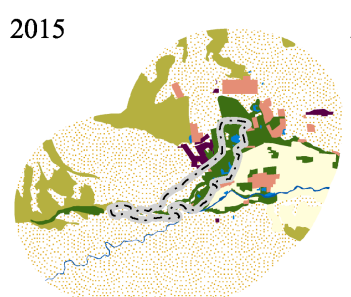

2000

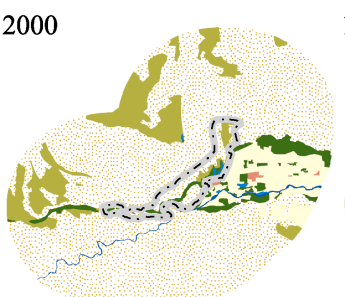

2010

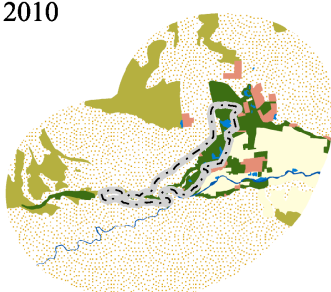

2005

1995

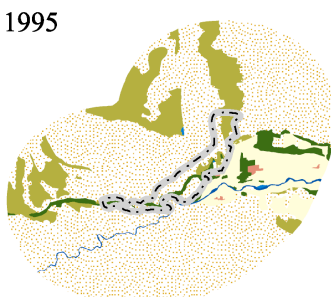

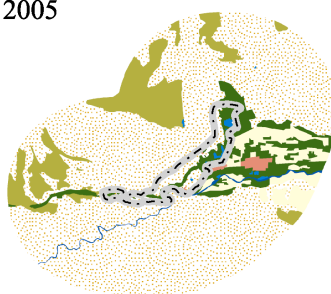

1990

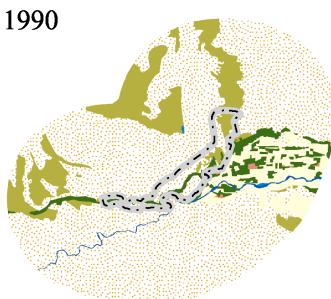

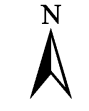

图例 Legend

- 沙坡头国家级自然保护区边界 Shapotou National Nature Reserve 防护林 Shelter forest 天然草地 Natural grassland 农田 Farm 荒漠 Desert

河流 River 湖泊 Lake 城建用地 Building 能源用地 Solar energy

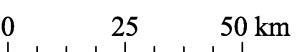

图2 1990-2015年研究区域遥感解译结果

Fig. 2 Interpretation result of study area between 1990 and 2015 


$$
\begin{gathered}
\text { 其中, } S=\sum_{i=1}^{n-1} \sum_{j=i+1}^{n} \operatorname{sign}\left(R_{j}-R_{i}\right) \\
\operatorname{sign}\left(R_{j}-R_{i}\right)=\left\{\begin{array}{l}
1, R_{j}-R_{i}>0 \\
0, R_{j}-R_{i}=0 \\
-1, R_{j}-R_{i}<0
\end{array}\right. \\
s(S)=\frac{n(n-1)(2 n+5)}{18}
\end{gathered}
$$

式中, $R_{j}$ 和 $R_{i}$ 分别表示第 $j$ 和第 $i$ 距离尺度下的人工 地物面积占比; sign 是符号函数; Mann-Kendall 统计 量 $Z$ 的取值在 $(-\infty,+\infty)$, 其符号表示变化趋势的方 向, 正值为上升趋势, 负值为下降趋势。将 MannKendall 统计量 $Z$ 在 0.05 和 0.01 置信水平上的显著 性检验结果划分为显著变化 $(|Z|>1.96)$ 和极显著变 化 $(|Z|>2.56),|Z| \leq 1.96$ 为变化不显著。Mann-Kendall 检验统计量 $Z$ 的计算在 Visual Studio 2017 编程环境 下实现。

使用SPSS 20.0软件对驱动力因子与空间近邻 效应趋势进行相关性分析。选取各环状区域内防护 林、农田、城镇用地和能源用地的面积占比作为驱 动力因子的指标, 选用Pearson相关系数, 相关系数 为正表明存在正相关, 反之为负相关; 相关系数的 绝对值越接近1, 相关性越强。同时对相关性系数在 0.05 和 0.01 置信水平上进行显著性检验。

\section{2 结果}

\section{1 遥感解译结果}

从土地利用类型解译结果(图2)中可以发现, 伴随时间推移, 研究区域内人类活动对土地利用类 型的改变作用不断深化。城镇用地面积在研究区域 内明显增多(表1), 2015年与2010年和1990年相比, 面积分别增加2,690 ha和8,490 ha。解译发现2010年
新增能源用地利用类型, 到2015年时面积为 $3,076 \mathrm{ha}$, 为中卫市在滕格里沙漠中建设的光伏发电基地。 1990-2015年期间，农田和防护林的面积分别增加 4,029 ha和4,702 ha。

随着时间的推移, 研究区域内人工地物面积及 景观格局不断扩大, 农田、防护林以及能源用地面 积持续增加, 人工地物的景观格局逐渐由镶嵌分布 向连片分布演变, 人为活动影响增强。

\section{2 空间近邻效应与变化趋势}

对1990-2015年6期研究区域内, 统计各距离尺 度下的人工地物占比, 获得空间近邻效应变化趋势 图(图3)。结果可以发现: 随着时间的推移, 人工地 物占比呈现增加趋势。2015年的人工地物占比在各 距离尺度内均高于其他年份。同时, 随着距离尺度 的增加, 各年份人工地物占比都出现了明显的下降 趋势。趋势变化可以划分为 3 个区间: 第一区间在距 离自然保护区 $1-5 \mathrm{~km}$ 尺度内, 各年份人工地物占比 出现不同程度的下降, 这一区间内的变化以 2005 年、 2010 年和 2015 年3期最为明显，下降幅度分别为 $43 \% 、 20 \%$ 和 $28 \%$; 第二区间在距离自然保护区6$10 \mathrm{~km}$ 尺度内, 各年份人工地物占比继续下降, 在 $10 \mathrm{~km}$ 处，人工地物占比稳定在 $10-13 \%$; 第三区间 在距离自然保护区11-20 km尺度内, 人工地物占比 下降速度明显减缓, 在距离自然保护区18 km之后, 各年份人工地物占比基本相同。

人工地物空间近邻效应Mann-Kendall统计量 $Z$ 值的检验结果(表2)表明, 在沙坡头国家级自然保护 区以外1-20 km范围内, 各年份的人工地物空间近 邻效应都表现出了不同显著性水平的下降趋势。在 第一区间内, 2015年和2005年呈现出显著下降的趋 势, Mann-Kendall统计量 $Z$ 值均为 -2.20 , 其他年份的

表1 各时期土地利用类型及其面积

Table 1 Land use type and area (ha) for each period

\begin{tabular}{lllllll}
\hline & 1990 & 1995 & 2000 & 2005 & 2010 & 2015 \\
\hline 防护林 Shelter forest & 17,498 & 10,536 & 13,592 & 23,990 & 21,878 & 22,200 \\
天然草地 Natural grassland & 38,971 & 41,608 & 34,462 & 34,742 & 35,026 & 38,393 \\
农田 Farm & 21,027 & 24,132 & 22,315 & 16,619 & 24,738 & 25,056 \\
荒漠 Desert & 224,391 & 225,600 & 230,718 & 224,165 & 213,015 & 203,397 \\
河流 River & 1,868 & 1,858 & 1,858 & 1,858 & 1,858 & 1,858 \\
湖泊 Lake & 195 & 195 & 885 & 1,246 & 1,592 & 1,479 \\
城镇用地 Building & 712 & 733 & 832 & 2,041 & 6,512 & 9,202 \\
能源用地 Solar energy & 0 & 0 & 0 & 0 & 42 & 3,076 \\
总计 Total & 304,661 & 304,661 & 304,661 & 304,661 & 304,661 & 304,661 \\
\hline
\end{tabular}




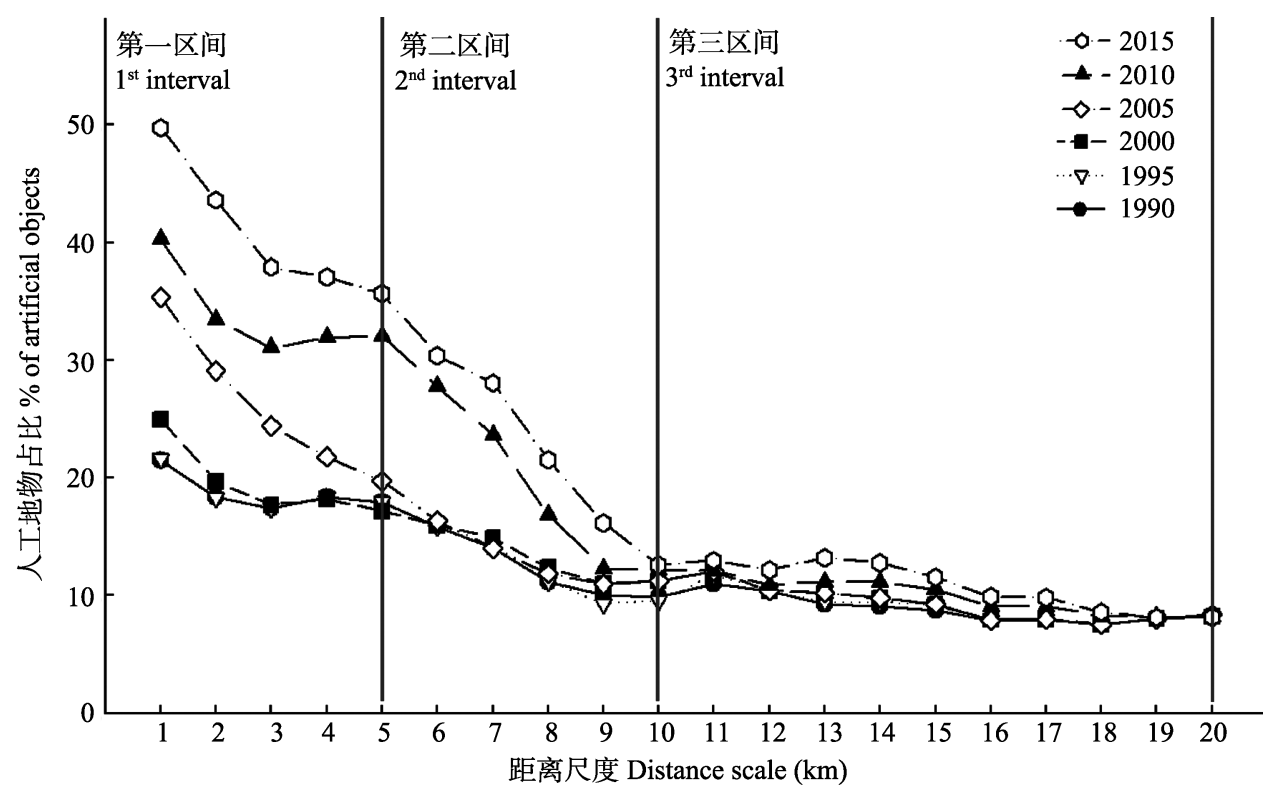

图3 1990-2015年研究区域人工地物空间近邻效应趋势图

Fig. 3 The trend of space neighborhood effect of artificial objects of study area between 1990 and 2015

表2人工地物空间近邻效应Mann-Kendall趋势检验统计量 $Z$ 值结果

Table 2 Mann-Kendall trend $Z$ test results on space neighborhood effect of artificial objects

\begin{tabular}{llllllll}
\hline & 距离尺度 Distance scale $(\mathrm{km})$ & 1990 & 1995 & 2000 & 2005 & 2010 & 2015 \\
\hline 第一区间 1st interval & $1-5$ & -0.73 & -0.73 & -1.96 & $-2.20^{*}$ & -1.47 & $-2.20^{*}$ \\
第二区间 2nd interval & $6-10$ & $-2.20^{*}$ & -1.96 & -1.96 & -1.96 & $-2.20^{*}$ & $-2.20^{*}$ \\
第三区间 3rd interval & $11-20$ & $-3.22^{* *}$ & $-3.22^{* *}$ & $-3.22^{* *}$ & $-3.22^{* *}$ & $-3.58^{* *}$ & $-3.58^{* *}$ \\
\hline
\end{tabular}

* 表示通过 0.05 置信水平的检验, 变化趋势具有显著性; ** 表示通过 0.01 置信水平的检验, 变化趋势具有极显著性。

* The change trend passed 0.05 confidence level test and was significant; ** The change trend passed 0.01 confidence level test and was very significant.

下降趋势未能通过 0.05 置信水平的检验; 在第二区间 内，2015年、2010年和1990年的下降趋势显著，均为 -2.20, 其他 3 个年份的Mann-Kendall统计量 $Z$ 值均为 -1.96, 可以说明下降趋势接近显著; 在第三区间上, 各年份的人工地物空间近邻效应下降趋势均通过了 0.01 置信水平的检验，表现出了极显著的下降趋势。

\section{3 相关因子分析}

空间近邻效应的驱动力因子相关性分析结果 (表3)表明，在不同年份和不同变化区间内各驱动力 因子的相关性和显著性有所不同。

从全区间上看，防护林与空间近邻效应的变化 趋势具有极显著的正相关性，相关性系数维持在 0.786-0.985; 农田与空间近邻效应的相关性表现为 正相关，相关性系数在 $0.360-0.756$ 之间，除2010年 外, 其他年份均通过了显著性检验; 城镇用地的相 关性系数呈现出了波动的变化规律, 2015年相关系 数最低(0.489), 并仅表现出显著性, 其他年份均为 极显著性; 能源用地自 2010 年出现, 相关系数由
0.490 变为 0.830 , 相关性和显著性都得到了增强。防 护林的栽植和经营在不同年份内与空间近邻效应 的相关性表现都较为明显，其次是农田和城镇用地， 能源用地的相关性在近年来有所增强。

从空间上看，第一区间内防护林表现出了与空 间近邻效应较强的正相关性，并且2005年和2015年 达到极显著水平; 第二区间内，城镇用地的相关性 增强，与防护林一起成为本变化区间内具有较高相 关性的驱动力因子，同时两者的多数均通过了显著 性检验; 第三区间内，农田取代了防护林和城镇用 地，成为在相关性和显著性上都较强的驱动力因 子。各变化区间内的主导驱动力因子的不同，表征 了该区间内人为活动的不同导向。随着与自然保护 区距离的增加，防护林的相关性减弱，城镇用地和 农田的相关性先后在第二区间和第三区间显现。

\section{3 讨论}

人工地物的出现表征了人类活动对自然环境 
表3 空间近邻效应的驱动力因子相关性分析结果

Table 3 The results of the correlation analysis of the driving factors of space neighborhood effect

\begin{tabular}{|c|c|c|c|c|c|c|c|c|c|c|c|c|c|c|}
\hline & & \multicolumn{4}{|c|}{1990} & \multicolumn{5}{|c|}{1995} & \multicolumn{4}{|c|}{2000} \\
\hline & & \multicolumn{2}{|c|}{$\begin{array}{l}\text { 防护林 } \\
\text { Shelter forest }\end{array}$} & $\begin{array}{ll} & \text { 农田 } \\
\mathrm{t} & \text { Farm }\end{array}$ & $\begin{array}{l}\text { 城镇用地 } \\
\text { Building }\end{array}$ & \multicolumn{2}{|c|}{$\begin{array}{l}\text { 防护林 } \\
\text { Shelter forest } \\
\end{array}$} & $\begin{array}{l}\text { 农田 } \\
\text { Farm }\end{array}$ & \multicolumn{2}{|c|}{$\begin{array}{l}\text { 城镇用地 } \\
\text { Building } \\
\end{array}$} & \multicolumn{2}{|c|}{$\begin{array}{l}\text { 防护林 } \\
\text { Shelter forest }\end{array}$} & $\begin{array}{l}\text { 农田 } \\
\text { Farm }\end{array}$ & $\begin{array}{l}\text { 城镇用地 } \\
\text { Building }\end{array}$ \\
\hline \multirow{6}{*}{$\begin{array}{l}\text { 第一区间 } 1 \mathrm{~s} \\
\text { 第二区间 } 2 \mathrm{n} \\
\text { 第三区间 } 3 \mathrm{r} \\
\text { 全区间 Entir }\end{array}$} & interval & \multicolumn{2}{|c|}{0.855} & -0.527 & 0.767 & \multicolumn{2}{|c|}{0.713} & -0.418 & \multicolumn{2}{|c|}{0.773} & \multicolumn{2}{|c|}{0.848} & -0.381 & $0.955^{*}$ \\
\hline & interval & \multicolumn{2}{|c|}{$0.949^{*}$} & 0.871 & $0.904^{*}$ & \multicolumn{2}{|l|}{$0.996^{* *}$} & $0.939^{*}$ & \multicolumn{2}{|c|}{$0.993^{* *}$} & \multicolumn{2}{|l|}{0.645} & $0.907^{*}$ & $0.994^{* *}$ \\
\hline & interval & \multicolumn{2}{|c|}{0.449} & $0.936^{* *}$ & -0.013 & \multicolumn{2}{|l|}{$0.682^{*}$} & $0.977^{* *}$ & \multicolumn{2}{|c|}{-0.399} & \multicolumn{2}{|c|}{$0.887^{* *}$} & $0.713^{*}$ & -0.273 \\
\hline & interval & \multicolumn{2}{|c|}{$0.959^{* *}$} & $0.594^{* *}$ & $0.635^{* *}$ & \multicolumn{2}{|l|}{$0.786^{* *}$} & $0.756^{* *}$ & \multicolumn{2}{|c|}{$0.606^{* *}$} & \multicolumn{2}{|c|}{$0.869^{* *}$} & $0.720^{* *}$ & $0.689^{* *}$ \\
\hline & \multicolumn{4}{|c|}{2005} & \multicolumn{5}{|c|}{2010} & \multicolumn{5}{|c|}{2015} \\
\hline & \multicolumn{2}{|c|}{ Shelter forest } & $\begin{array}{l}\text { 农田 } \\
\text { Farm }\end{array}$ & $\begin{array}{l}\text { 城镇用地 } \\
\text { Building }\end{array}$ & $\begin{array}{l}\text { 防护林 } \\
\text { Shelter forest }\end{array}$ & $\begin{array}{l}\text { 农田 } \\
\text { Farm }\end{array}$ & $\begin{array}{l}\text { 城镇用地 } \\
\text { Building }\end{array}$ & \multicolumn{2}{|c|}{$\begin{array}{ll}\text { 也 能源用地 } \\
\text { Solar energy }\end{array}$} & \multicolumn{2}{|c|}{$\begin{array}{l}\text { 防护林 } \\
\text { Shelter forest }\end{array}$} & $\begin{array}{l}\text { 农田 } \\
\text { Farm }\end{array}$ & $\begin{array}{l}\text { 城镇用地 } \\
\text { Building }\end{array}$ & $\begin{array}{l}\text { 能源用地 } \\
\text { Solar energy }\end{array}$ \\
\hline $\begin{array}{l}\text { 第一区间 } \\
\text { 1st interval }\end{array}$ & $0.993^{* *}$ & & -0.620 & 0.649 & 0.638 & -0.404 & 0.647 & 0.973 & & 0.962 & & 0.110 & 0.186 & -0.583 \\
\hline $\begin{array}{l}\text { 第二区间 } \\
\text { 2nd interval }\end{array}$ & 0.602 & & $0.892^{*}$ & 0.473 & $0.957^{*}$ & 0.530 & $0.948^{*}$ & - & & 0.987 & & -0.038 & $0.891^{*}$ & $0.901^{*}$ \\
\hline $\begin{array}{l}\text { 第三区间 } \\
\text { 3rd interval }\end{array}$ & $0.846^{* *}$ & & $0.729^{*}$ & - & 0.618 & $0.912^{* *}$ & 0.073 & - & & 0.794 & & $0.903^{* *}$ & $0.751^{*}$ & 0.041 \\
\hline $\begin{array}{l}\text { 全区间 } \\
\text { Entire interva }\end{array}$ & $0.985^{* *}$ & & $0.538^{*}$ & $0.610^{* *}$ & $0.959^{* *}$ & 0.360 & $0.662^{* *}$ & 0.49 & & 0.976 & & $0.533^{*}$ & $0.489^{*}$ & $0.830^{* *}$ \\
\hline
\end{tabular}

* 表示通过 0.05 置信水平的检验，相关性具有显著性; ** 表示通过 0.01 置信水平的检验，相关性具有极显著性; - 表示该项驱动力因子 $($ 土地 利用类型)在区间内不存在。

* The correlation passes 0.05 confidence level test and is significant; ** The correlation passes 0.01 confidence level test and is extremely significant;

- The driving factor (land use type) does not exist in the interval.

的改造, 是目前自然保护区生态环境评估的重要关 注对象。以往的研究多是基于自然保护区内外变化 的对比分析, 结合随机抽样和空白对照的方式进行 统计评估(Sánchez-Azofeifa et al, 2003; Oliveira et al, 2007)。本研究从人工地物时空变化的角度出发, 着 眼于自然保护区周边区域的空间范围，通过对研究 区域空间上的分割和不同时期的人工地物格局的 提取, 引入Mann-Kendall趋势分析法和驱动因子的 相关性检验分析, 构建了一种自然保护区人工地物 空间近邻效应的评估技术。通过在沙坡头国家级自 然保护区的研究发现, 本技术可以在时空序列上对 自然保护区的人工地物空间近邻效应作出评估, 进 而有助于分析空间近邻效应的变化区间和作用距 离, 同时识别驱动因子等。

随着我国自然保护区建设水平的不断提高, 部 分自然保护区凭借得天独厚的自然景观或珍稀生 物资源开展了生态旅游和环境教育, 探索与周边社 区协调发展的模式(苏杨, 2005; 王昌海等, 2010)。 一种较普遍的观点认为, 自然保护区的建立对其内 部和外部的生态环境与生物多样性同时带来积极 作用(Leverington et al, 2010; Richard et al, 2010)。然 而, 从本研究案例来看, 沙坡头国家级自然保护区 外围人工地物占比逐年升高, 尤其以保护区附近 5 $\mathrm{km}$ 距离范围内较为明显。这种外围的人为活动的增 强可能会对保护区内的生态安全造成不利影响。

沙坡头国家级自然保护区周边土地利用受人 为作用影响强烈, 其人工地物的空间近邻效应随距 离增加呈现出下降趋势。分析认为, 防护林营造和 旅游业发展是造成这一现象的主要原因。防护林营 造是研究区域内主要的土地利用转变途径。作为荒 漠和草原生态系统的过渡地带, 研究区内大量的草 方格、固沙植物带和防护林体系抵挡了腾格里沙漠 南进。自20世纪50年代起, 中国科学院沙漠研究实 验站便在沙坡头开展了我国最早的沙漠科学研究 (李新荣等, 2016)。1978年, 宁夏全境被列入我国第 一批三北防护林建设工程范围 (http://tnsf.forestry. gov.cn/site/1/html/zjsb/list_1027.htm)。通过一系列的 自然生态保护和恢复工程, 宁夏全省森林覆盖率由 1975年的 1.4\% (朱海娟，2015)提升到2015年的 $13.8 \%$ (2015年宁夏回族自治区政府工作报告)。人 工造林极大地改善了沙坡头区域的生态环境, 加大 了沙坡头国家级自然保护区外围人工地物占比, 成 为人工地物空间近邻效应在不同时间和不同空间 上的主要驱动力因子。另一方面, 旅游业发展带动 了基础设施建设用地的开发。沙坡头国家级自然保 护区的黄河和沙漠景观吸引了国内外众多游客。自 
1984年沙坡头自然保护区(景区)建立以来, 游客数 量由 6 万人次激增到 2015 年的 384 万人次 (尹郑刚, 2012; 中卫市2015年国民经济和社会发展统计公报 http://www.nxzw.gov.cn/gk/tjgb/22983.htm)。商业活 动都是在靠近客源、靠近市场的地方进行的(孙忠峰, 2007)。在沙坡头国家级自然保护区周边, 机场、公 路、餐饮、住宿等配套设施的建设, 以及城镇和乡 村居民点分布、垦殖区的扩张等因素, 都加速了保 护区周边土地利用类型的改变。

自然保护区的设计规划和管护是一项系统的 工作, 国内外有关研究已经提出“动态自然保护区 及其区划”这一概念(崔国发, 2013; 呼延佼奇等, 2014), 认为自然保护区的管护范围应根据保护对 象的活动和变化进行适时调整。对自然保护区而言, 其内部的自然资源和生态环境受到了保护, 但是自 然保护区外的自然资源利用行为仍须有关政策的 管控和科学的设计。划定的保护区边界并不能阻断 或隔离生物与环境的相互作用，同样地，也不代表 未来保护区的范围不会发生变化。因此, 应对自然 保护区建立后带来的空间近邻效应予以关注，并将 相关研究成果运用到评估工作中。

致谢：感谢百度架构师贾建桥在Mann-Kendall编程 实现及检验中给予的帮助。

\section{参考文献}

Abesamis RA, Russ GR (2005) Density-dependent spillover from a marine reserve: long-term evidence. Ecological Applications, 5, 1798-1812.

Amin A (2016) Exploring the role of economic incentives and spillover effects in biodiversity conservation policies in sub-Saharan Africa. Ecological Economics, 127, 185-191.

Chen JN (2016) Review and outlook at the 60th anniversary of China's nature reserves. Man and the Biosphere, (6), 1-3. (in Chinese) [陈吉宁 (2016) 中国自然保护区60周年回顾 和展望. 人与生物圈, (6), 1-3.]

Chen LD, Li XZ, Fu BJ, Xiao DN, Zhao WW (2014) Development history and future research priorities of landscape ecology in China. Acta Ecologica Sinica, 34, 3129-3141. (in Chinese with English abstract) [陈利顶, 李秀珍, 傅伯杰, 肖笃宁, 赵文武 (2014) 中国景观生态学发展历程与未 来研究重点. 生态学报, 34, 3129-3141.]

Chen XY, Shao S, Tian ZH, Xie Z, Yin P (2016) Impacts of air pollution and its spatial spillover effect on public health based on China's big data sample. Journal of Cleaner Production, 142, 915-925.

Cui GF (2013) Dictionary of Nature Conservology. China For- estry Publishing House, Beijing. (in Chinese) [崔国发 (2013) 自然保护区学词典. 中国林业出版社, 北京.]

Deng XY, Liu Y, Liu ZH, Yao JQ (2017) Temporal-spatial dynamic change characteristics of evapotranspiration in arid region of Northwest China. Acta Ecologica Sinica, 37, 2994-3008. (in Chinese with English abstract) [邓兴耀, 刘 洋, 刘志辉, 姚俊强 (2017) 中国西北干旱区蒸散发时空 动态特征. 生态学报, 37, 2994-3008.]

Department of Nature and Ecology Conservation of Ministry of Environmental Protection, Nanjing Institute of Environmental Science of Ministry of Environmental Protection (2006) National Nature Reserves of China. China Environmental Science Press, Beijing. (in Chinese) [国家环境保护 总局自然生态保护司, 国家环境保护总局南京环境科学 研究所 (2006) 中国国家级自然保护区. 中国环境科学 出版社, 北京.]

Ewers R, Rodrigues A (2008) Estimates of reserve effectiveness are confounded by leakage. Trends in Ecology \& Evolution, 23, 113-116.

Fan ZM, Zhang X, Li J, Yue TX, Liu JY, Sun XF, Xiang B, Kuang WH (2012) Transition trends of land-cover in national nature reserves of China. Acta Geographica Sinica, 67, 1623-1633. (in Chinese with English abstract) [范泽孟, 张轩, 李婧, 岳天祥, 刘纪远, 孙晓芳, 香宝, 匡文慧 (2012) 国家级自然保护区土地覆盖类型转换趋势. 地理 学报, 67, 1623-1633.]

Hoaglin D, Mosteller F, Tukey J (2000) Understanding Robust and Exploratory Data Analysis. Wiley, New York.

Howard PC, Davenport TRB, Kigenyi FW, Viskanic P, Baltzer MC, Dickinson CJ, Lwanga J, Matthews RA, Mupada E (2000) Protected area planning in the tropics: Uganda's national system of forest nature reserves. Conservation Biology, 14, 858-875.

Huyan JQ, Xiao J, Yu BW, Xu WH (2014) Research progress in function zoning of nature reserves in China. Acta Ecologica Sinica, 34, 6391-6396. (in Chinese with English abstract) [呼延佼奇, 肖静, 于博威, 徐卫华 (2014) 我国 自然保护区功能分区研究进展。生态学报, 34, 6391-6396.]

Leverington F, Costa KL, Pavese H, Lisle A, Hockings M (2010) A global analysis of protected area management effectiveness. Environmental Management, 46, 685-698.

Li XJ, Li GP, Zeng G, Gu CL, Lin BY, Zhang WZ (2006) Economic Geography, 2nd edn. Higher Education Press, Beijing. (in Chinese) [李小建, 李国平, 曾刚, 喜成林, 林 炳耀, 张文忠 (2006) 经济地理学, 第二版. 高等教育出 版社, 北京.]

Li XR, Zhou HY, Wang XP, Liu LC, Zhang JG, Chen GX, Zhang ZS, Liu YB, Tan HJ, Gao YH (2016) Ecological restoration and recovery in arid desert regions of China: a review for 60-year research progress of Shapotou Desert Research and Experiment Station. Journal of Desert Research, 36, 247-264. (in Chinese with English abstract) [李新荣, 周海燕, 王新平, 刘立超, 张景光, 陈国雄, 张志山, 刘 玉冰, 谭会娟, 高艳红 (2016) 中国干旱沙区的生态重建 与恢复: 沙坡头站60年重要研究进展综述. 中国沙漠, 36, 247-264.] 
Liu FZ, Zhang JL, Wang L, Yang ZW, Cui GF (2016) Vegetation growth and conservation efficacy assessment in the southern part of the Gansu Anxi National Nature Reserve in Hyper-Arid Desert. Acta Ecologica Sinica, 36, 1582-1590. (in Chinese with English abstract) [刘方正, 张建亮, 王亮, 杨增武, 崔国发 (2016) 甘肃安西极旱荒漠国家级自然 保护区南片植被长势与保护成效. 生态学报, 36, 1582-1590.]

Liu NF, Hao YM, Wu HB (2005) A Comprehensive Scientific Survey of Ningxia Shapotou National Nature Reserve. Lanzhou University Press, Lanzhou. (in Chinese) [刘迺发, 郝 耀明, 吴洪斌 (2005) 宁夏沙坡头国家级自然保护区综 合科学考察. 兰州大学出版社, 兰州.]

Maiorano L, Falcucci A, Boitani L (2008) Size-dependent resistance of protected areas to land-use change. Royal Society Proceedings B: Biological Sciences, 275, 1297-1304.

Nagendra H, Tucker C, Carlson L, Southworth J, Karmacharya M, Karna B (2004) Monitoring parks through remote sensing: studies in Nepal and Honduras. Environmental Management, 5, 748-760.

Nepstad D, Schwartzman S, Bamberger B, Santilli M, Ray D, Schlesinger P, Lefebvre P, Alencar A, Prinz E, Fiske G (2006) Inhibition of Amazon deforestation and fire by parks and indigenous lands. Conservation Biology, 20, 65-73.

Oliveira PJ, Asner GP, Knapp DE, Almeyda A, Galvángildemeister R, Keene S, Raybin RF, Smith RC (2007) Land-use allocation protects the Peruvian Amazon. Science, 317, 1233-1236.

Richard F, Eve M, Kerrie W, Josie C, Hedley G, James W, Carissa K, David G, Hugh P (2010) Replacing underperforming protected areas achieves better conservation outcomes. Nature, 466, 365-367.

Russ GR, Alcala AC, Maypa AP, Calumpong HP, White AT (2004) Marine reserve benefits local fisheries. Ecological Applications, 2, 597-606.

Sánchez-Azofeifa GA, Daily GC, Pfaff ASP, Busch C (2003) Integrity and isolation of Costa Rica's national parks and biological reserves: examining the dynamics of land-cover change. Biological Conservation, 109, 123-135.

Su Y (2005) The research and practice of harmonized development of the nature reserves and their ambient communities in west China. Forestry and Society, 13(1), 27-34. (in Chinese with English abstract) [苏杨 (2005) 中国西部自 然保护区与周边社区协调发展的研究与实践. 林业与社 会, 13(1), 27-34.]

Sun ZF (2007) Research on Agglomeration of FDI in Manufacturing Industries and Regional Economy Development. $\mathrm{PhD}$ dissertation, Tianjin University, Tianjin. (in Chinese with English abstract) [孙忠峰 (2007) 制造业外资聚集与 区域经济发展研究. 博士学位论文, 天津大学, 天津.]
Tošić I (2004) Spatial and temporal variability of winter and summer precipitation over Serbia and Montenegro. Theoretical and Applied Climatology, 77, 47-56.

Wang CH, Wen YL, Hu CD, Si KC (2010) Research progress on harmonious development of nature reserves and surrounding communities. Issues of Forestry Economics, 30, 486-492. (in Chinese with English abstract) [王昌海, 温亚 利, 胡崇德, 司开创 (2010) 中国自然保护区与周边社区 协调发展研究进展. 林业经济问题, 30, 486-492.]

Wang MX, Yan JP, Li SS (2014) Spatial-temporal variation and the tendency of droughts and floods on the southeast coast of China over 54 years. Resource Science, 36, 2307-2315. (in Chinese with English abstract) [王米雪, 延 军平, 李双双 (2014) 1960-2013年中国东南沿海地区旱 涝时空变化特征及其趋势分析. 资源科学, 36, 2307-2315.]

Wang W, Xin LJ, Du JH, Chen B, Liu FZ, Zhang LB, Li JS (2016) Evaluating conservation effectiveness of protected areas: advances and new perspectives. Biodiversity Science, 24, 1177-1188. (in Chinese with English abstract) [王伟, 辛利娟，杜金鸿，陈冰，刘方正，张立博，李俊生 (2016) 自然保护地保护成效评估: 进展与展望. 生物多样性, 24, 1177-1188.]

Wittemyer G, Elsen P, Bean WT, Burton AC, Brashares JS (2008) Accelerated human population growth at protected area edges. Science, 321, 123-126.

Wright SJ, Sanchez-Azofeifa GA, Portillo-Quintero C, Davies D (2007) Poverty and corruption compromise tropical forest reserves. Ecological Applications, 5, 1259-1266.

Yin ZG (2012) Subjective and Objective System in Desert Tourism and Scenic Areas' Competitive Superiority: Typical Case Study. PhD dissertation, Lanzhou University, Lanzhou. (in Chinese with English abstract) [尹郑刚 (2012) 沙 漠旅游主客体系统及景区竞争优势: 典型案例研究. 博 士学位论文, 兰州大学, 兰州.]

Yuan LH, Jiang WG, Shen WM, Liu YH, Wang WJ, Tao LL, Zheng H, Liu XF (2013) The spatio-temporal variations of vegetation cover in the Yellow River Basin from 2000 to 2010. Acta Ecologica Sinica, 33, 7798-7806. (in Chinese with English abstract) [袁丽华, 蒋卫国, 申文明, 刘颖慧, 王文杰，陶亮亮，郑华，刘孝富 (2013) 2000-2010年黄河 流域植被覆盖的时空变化. 生态学报, 33, 7798-7806.]

Zhu HJ (2015) Study on Synthetic Benefit Evaluation on Desertification Control in Ningxia Hui Autonomous Region. $\mathrm{PhD}$ dissertation, Northwest A \& F University, Yangling. (in Chinese with English abstract) [朱海娟 (2015) 宁夏荒 漠化治理综合效益评价研究. 博士学位论文, 西北农林 科技大学，杨凌.]

(责任编委：唐志尧 责任编辑: 时意专)

\section{附录 Supplementary Material}

附录1 基于人工地物时空变化的空间近邻效应评估技术路线

Apendix 1 The technical route of space neighborhood effect assessment based on temporal and spatial change of artificial objects http://www.biodiversity-science.net/fileup/PDF/2017134-1.pdf 
刘方正，张 鹏，张玉波，陈冰，杜金鸿，王伟，李俊生. 基于人工地物时空变化的自然保护区空间近邻效应评估：以沙坡头 国家级自然保护区为例. 生物多样性, 2017, 25 (10): 1105-1113.

http://www.biodiversity-science.net/fileup/PDF/2017134-1.pdf

\section{附录1 基于人工地物时空变化的空间近邻效应评估技术路线}

Apendix 1 The technical route of space neighborhood effect assessment based on temporal and spatial change of artificial objects http://www.biodiversity-science.net/fileup/PDF/2017134-1.pdf

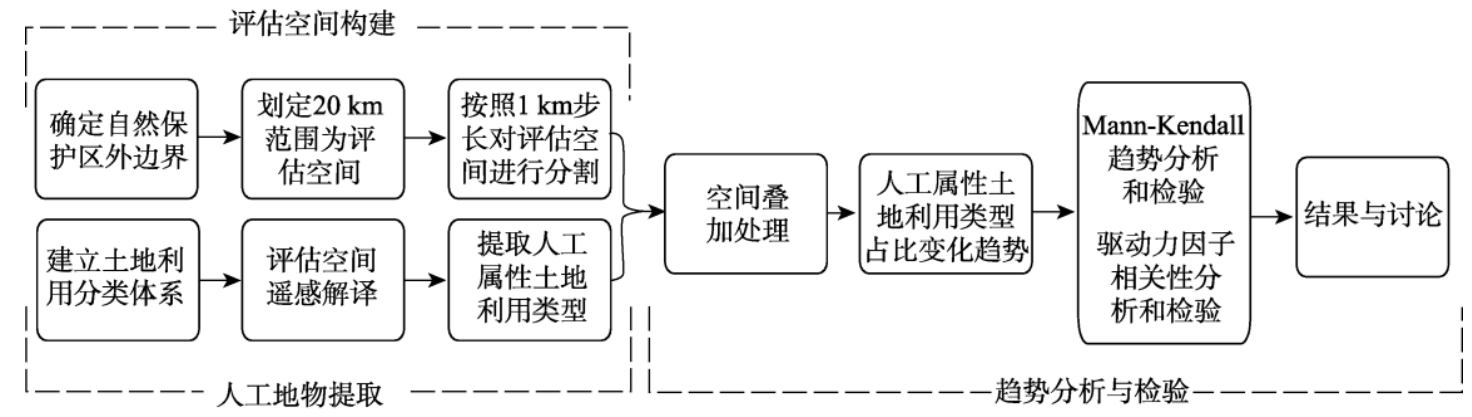

